\title{
Russian Management Style: A Game Theory Approach to Evaluating Decision Making*
}

\author{
Robin Matthews / Ara Yeghiazarian ${ }^{* *}$
}

This paper springs from the practical problem of designing management training programs to improve decision making by Russian managers in the market economy. We approach the problem by attempting to identify any clustering (focal points) in their decision making, and investigating the impact upon the efficiency of firms in a simulation game. We then consider the implications for a real economy and for the orientation of management training programs by asking whether these focal points inhibit effective decision making and efficient results. We believe that our methodology has wide implications for identifying management training needs generally, and is not confined to the Russian managers who provide the empirical basis for this paper.

Ausgangspunkt dieser Arbeit sind praktische Probleme der Entwicklung von Managementtrainingsprogrammen zur Verbesserung der Entscheidungsfindung russischer Manager im Hinblick auf marktwirtschaftliche Erfordernisse. Dazu wurden zunächst Schwerpunktbereiche der Entscheidungsfindung identifiziert und deren Auswirkungen auf die Effizienz mittels Simulationen überprüft. Aus den Ergebnissen wurde die notwendige Ausrichtung von Trainingsprogrammen abgeleitet. Wir glauben, daß unsere Methode zur Identifikation von Weiterbildungsbedarf allgemein verwertbar und nicht nur auf russische Manager anwendbar ist.

Manuscript received: 9.8.96, revised: 29.10.97, accepted: 12.1 .98

** Robin Matthews, born 1945, Professor of International Business Policy, Kingston University Business School; Research interests: Game theory, Economics of transition, Complexity.

Ara Yeghiazarian, born 1957, Senior Lecturer Information Systems at Kingston University Business School; Research interests: Cross-cultural management decision making, Economics of transition.

Mail address: Kingston University Business School, Kingston Hill, Kingston on Thames, Surrey KT2 7LB, UK

Tel.: +4401815472000

Email: r.matthews@kingston.ac.uk 


\section{Introduction $^{18}$}

The paper reports on the methodology and results of a project whose aim is to identify constraints on the developing market economy that stem from the way Russian managers make decisions and the type of decisions they make. This approach is seen as complementary to work on reforming the Russian economy at a macro level. (see for example Dietz 1992; Dyker 1992; Economist Intelligence Unit, Sachs 1995, 1994(a) and (b); Sachs/ Wyplosz 1994). We are looking for any clustering of decisions around focal points that may inhibit or enhance decision making by Russian managers from the point of view of the firms for which they have responsibility, and for the economy in general. The project has practical purpose of helping to orient training effectively on management programs generally.

We describe our methodology in the next section. The theoretical structure is based on observations of Russian managers taking part in Managers' Programme in Kingston Business School (Hicks 1995; Yeghiazarian/ Matthews 1995). They have wide ranging business experience in State and private owned enterprises. They are drawn from both large and small businesses. Many could be classified as entrepreneurs. Their industries range over much of the Standard Industrial Classification, including labour intensive industries such as mining, building \& construction, capital intensive industries such as heavy engineering chemicals and oil, through to fast evolving technical and service industries such as computing, software houses, telecommunications, media, supermarkets, consulting and advertising.

We report on the focal points we have identified in managerial behaviour in a business simulation game. The game, TOPEXEC ${ }^{19}$, has been under continuous development on a range of undergraduate, postgraduate and executive programs in companies, including Boeing, BT, Shell in the USA and Europe for over 10 years. The simulation has evolved both in terms of updating the econometric database and information architecture. There is no limit to number of iteration of

18 The Thatcher and Rothschild Foundations provided the financial support the International Managers Program by the Business School of Kingston University. The Knowhow Fund (Training and Academic Links) of the British Council supported the setting up of a business planning course jointly by Kingston Business School and the Academy of National Economy under the Government of the Russian Federation. We emphasize that finance from these bodies was provided and used for the purpose of designing and operating practical training courses for Russian managers but we would like to acknowledge that this research is one of the unplanned spin-offs. We hope it is of interest to a wider audience.

19 The authors would like to thank Professor Al Shreiber of University of Washington at Seattle, the pioneer of the TOPEXEC Business Management Game. We are also grateful to Mr Ken Harry who has been a major contributor and user of the game for several years, and to Mrs Eve Hicks for her collaboration on earlier versions of the paper. 
game but Russian mangers are restricted by time to eight. At the end of each iteration, players of TOPEXEC are provided with detailed financial statements and costing data relating to their own company. This enables them to evaluate past decisions, and if necessary revise them. Although they have only limited information about rivals' strategies, they are given the opportunity to negotiate sales and purchases of inventory or to form strategic alliances. Strategic decision variables include prices, outputs, investment, marketing expenditures, research and development, and inventory. Players respond to their interpretation and analysis of business data, rivals strategies, and to changes in the business environment simulated by quarterly time series data on factors such as interest rates, GNP, and activity indices, including prices and employment.

To achieve the practical purpose and aims we have developed a methodology based upon the theory of focal points. So the paper outlines the theory of focal points, and our developments of the theory. The aims of the paper are as follows: i) to outline and theory focal points and their significance for management decision making, ii) to identify focal points, using data on Russian managers decision making in a simulation game, iii) to comment upon the significance of the focal points which we have identified, firstly for the Russian economy, and secondly for the training of Russian managers. Our results raise significant issues that are too often ignored both in policy prescriptions for Russia and in management training.

The paper is organised into three further sections. The next section, section two, outlines the methodology of our approach. In the third section, we identify focal points. In the fourth, we make some remarks on their significance.

\section{Methodology}

This section is in two parts. In the first part we outline the theory of focal points which was originally developed by Schelling (1960), and Kreps (1990). In the second part we describe the procedures we use to identify focal points.

\subsection{The theory of focal points}

The theory of focal points is well developed, but as far as we can detect its implications for management science have not previously been investigated, so our paper represents a novel approach. The emphasis is on behaviour on the micro level: on interactive decisions within firms and between them. We attempt to identify focal points, or to use another metaphor, attractors, around which managerial decisions cluster, and assess their effects on the market economy through the medium of a simulation game.

The notion of Nash equilibrium is central to focal points (Nash 1951). A Nash equilibrium in a game corresponds to a strategy that a player has no incentive to revise, provided that other players to not revise their strategies. The notion of 
focal points captures a recurrent theme in social sciences; the idea of hidden order. It appears in number of forms that are variations on the theme of the Invisible Hand. Focal points and focal equilibria are wider concepts in two senses: i. they apply generally, to any ordering, or reconciling principles, or spontaneous agreements, existing in individual or group psychology, or in culture, that enable people to choose between alternative Nash equilibria; ii. they may imply suboptimal as well as optimal behaviour.

We are not concerned here with problems of the existence of equilibrium, but with situations (simulation games, or interactions in a real market setting) where there is a multiplicity of possible equilibria, and a large number of players. Dealing with multiple potential Nash equilibria, Schelling, examined conditions that may cause players in a game to expect each other to implement a particular equilibrium. When this happens, the expected equilibrium becomes self fulfilling. Schelling called this phenomenon a focal point effect. A focal point equilibrium has some property that conspicuously distinguishes it from all others.

The following example, illustrating focal points was provided by Kreps (1989, 1990). Consider a game between two players, both American college students. They are presented with a list of eleven cities, (New York, Kansas City, Dallas, Denver, Chicago, Los Angeles, Phoenix, Boston, Philadelpia, San Francisco, and Atlanta), each of which has been given an arbitrary index, ranking its importance to commerce, the arts, and so on. The students know that New York scores highest with 100 points, and Kansas City, the lowest, with 1. Each student is asked to choose a subset of cities independently without consulting the other. One is told that he must list Boston: the other that he must list San Francisco. After the lists are drawn up they are compared. If a city appears on one list and not the other, the student listing that city wins as many dollars as the city's index. If a city appears on both lists, each loses twice as many dollars as the cities index. If the students manage to partition the eleven cities between them, this triples their total winnings.

In pure strategies, the game has 512 Nash equilibria. When it is played though, there is significant co-ordination. The Boston list nearly always contains New York, and Philadelphia, and less frequently, Chicago. Los Angeles, Phoenix, and Denver are invariably included on the San Francisco list, and sometimes, but less frequently, Dallas, and Kansas City. The reason, apparent to people familiar with the geography of the United States, is that choices are based upon which cities are located to the east, and which to the west, of the Mississippi river. Sometimes a Sunbelt/Snowbelt division is chosen, but the joint presence of Miami and Atlanta, both in the sunbelt usually causes this principle to be rejected.

Many examples of focal points are provided in Schelling's (1960) book. Simple qualitative factors underlie focal points. Symmetry and uniqueness seem to be 
important in selecting principles. In games involving division of payoffs, the symmetric notions of equity, or efficiency, often become organising principles. When one ordering principle defines a unique equilibrium, and an alternative suggests many, the first tends to be applied (Myerson 1991). Cultural norms may be important, as for example in the listing of cities. The experimental work of Roth and Schoumaker (1983) suggests that implicit agreements often arise through a process of adaptive expectations: learning from the experience about how others have played in the past, affects a players current and future behaviour.

\subsection{The data set}

The work reported here is an application of the theory of focal points to management decision making. The data set we used to identify focal points is based upon evidence from 86 Russian managers, participating on the International Managers Programs over the period 1993-97. Managers are aged between 25-40. They have wide ranging business experience prior to coming on the course. They are drawn from both large and small businesses. Many could be classified as entrepreneurs. Examples of their industries include labour intensive industries such as mining, building and construction through to fast evolving industries such as computing, software houses, telecommunications, media and advertising. Less than $10 \%$ of them have visited UK previously, although the majority of them had business experience with at least one or more country outside the Eastern block during the pervious five years. Although we have evidence from Russian managers on programmes prior to 1993, and evidence from number of case studies (Matthews/ Harry 1993), we have not included them explicitly in our analysis, but we have taken them into account in our commentary upon the results.

\subsection{The simulation game}

Our results are based on successive iterations of a simulation game TOPEXEC. The game consists of 2 simulation years (ie 8 decision making processes). The participants in each company receive nearly 1000 item of information about the company on each run, and they have to make 20-30 decisions for subsequent run. The simulation is subject to random shocks and noise from real macro economic data which is fed into model. Decisions range over pricing, marketing expenditures, research and development, stock control, financial reporting, and loan management.

\section{Focal points in russian management}

We begin with two general observations that underlie the elements in the table as a whole. 
i) A marked characteristic of the behaviour of Russian managers is that they seem to perceive the market economy as a zero sum game, having fixed total payoffs to be distributed among participants; in aggregate gains are seen as being matched exactly by losses.

ii) Russian players of the game attempt to maximise profits, but this is carried out as we might expect with bounded rationality (Simon 1982): they have limited information and powers of calculation. Short time horizons are evidence of rationality: discount rates that incorporate expected inflation and other risks mean that longer term earnings can rationally be ignored. Also we note that as expected inflation falls, so time horizons seem to lengthen. Competitive advantage seems to be defined by Russian decision makers, not so much by profitability (cost structures are higher), but by the leverage that market share gives in setting prices.

In successive iterations of the game by the eight cohorts of Russian mangers we observed a set of focal points that are summarised in Table 1 .

Table 1: Focal points in Russian management decision making

\begin{tabular}{|c|c|}
\hline Focal Point & Strength of clustering \\
\hline \multicolumn{2}{|l|}{ MANAGERIAL GOALS } \\
\hline Bounded profit maximisation & Strong clustering \\
\hline Perception of the market as a zero sum game & Strong clustering \\
\hline Positive utility for stocks & Weak clustering \\
\hline Short time horizons & $\begin{array}{l}\text { Strong clustering but adaptation over time as expected } \\
\text { inflation declines }\end{array}$ \\
\hline \multicolumn{2}{|l|}{ COMPANY BEHAVIOUR } \\
\hline Rigid pricing & Strong clustering \\
\hline Limited arbitrage & Strong clustering \\
\hline Poor controls & Strong clustering \\
\hline
\end{tabular}

Considering the elements in Table 1 in some detail we list a number of findings.

(a) Generally prices are relatively high in Russian games. Games involving Western players have lower prices, and consequently higher sales. However a more important feature is the rigidity of prices.

(b) Russian companies in the simulation frequently lose sales through shortages of finished goods, which could be rectified by exchange of stocks that exist within the system at a given time. Among Russian firms, there are significant differences in levels of stocks held, in terms of raw materials, work in progress, and finished goods. Stock levels are relatively higher on average than in Western games, but stocks are poorly distributed in terms of final customer demand. There is marked reluctance by firms holding excess stocks to sell them 
to other firms who are experiencing excess demand. For example in a typical game we observe stocks increasing by more than $50 \%$ and prices as a whole finished goods rising by $20 \%$. We would normally expect the correlation to be negative rather than positive, with prices of finished goods tending to be reduced in the face of rising stock levels; as the table shows the relationship is predominantly positive at the cumulative level. At the same time as some firms are experiencing stock shortages, others have excess supplies [see Table 2].

(c) Another way of expressing the previous paragraph is to say that arbitrage among Russian firms in the simulation is distinctly low. Russian managers tend to see inter company trade as a zero sum game, and strategic alliances, subcontracting, and even straightforward sales of stocks are excluded from their decision set. The reason for this seems to be that the sale of scarce stocks will simply result in the surrender of competitor advantage to rivals since in a zero sum game there are no net overall gains to be made from such an exchange.

(d) Although unit costs of production are often higher, because of smaller volumes of production, and excessively large stocks, overall profitability of Russian games is relatively high in comparison to games played by Western players. Low levels of price competition, together with price leadership by the dominant firm, leads to the high price structure in Russian games.

As compared to a typical game played by UK and USA managers, the overall result of Russian games is that their economy, defined by aggregate output of their game, tends to be smaller, and economic efficiency, measured by consumer surplus, tends to be lower. The average cost of finished goods is relatively high, due not only to poor inventory policy noted above, but also to excessive expenditures on marketing and under provision for research and development, and maintenance. In their smaller economy, Russian teams end up with more profitable companies operating with greater $X$ inefficiency (Leibenstein 1966), taking the form of higher unit costs, and lower asset utilisation.

The results of this section are summarised in Figure 1. Constant costs are assumed for convenience, hence the supply curves MS and NS' are horizontal. The vertical distance between the curves illustrates $X$ inefficiency. Outputs in the Russian game are smaller by the amount $\mathrm{KB}$, and prices higher, by RP, than the efficient market quantity price combination. Higher unit costs are represented by NM. Area HGJ represents the additional loss of consumer surplus through restricted output: in addition, area NMXT is lost through higher opportunity costs of production. 
Table 2: Excess demand and supply at the firm and economy level ${ }^{20}$

\begin{tabular}{|c|c|c|c|c|c|c|c|c|}
\hline \multirow[b]{2}{*}{ Year } & \multirow[b]{2}{*}{ Quarter } & \multirow[b]{2}{*}{ Period } & \multicolumn{2}{|c|}{ Company A } & \multicolumn{2}{|c|}{ Company B } & \multicolumn{2}{|c|}{ Company C } \\
\hline & & & Price changes & Stock changes & Price changes & Stock changes & Price changes & Stock changes \\
\hline & & & {$[\mathbf{P}(t+1)-\mathbf{P}(t)] / \mathbf{P}(t)$} & {$[Q(t+1)-Q(t)] / Q(t)$} & {$[\mathbf{P}(t+1)-P(t)] / P(t)$} & {$[Q(t+1)-Q(t)] / Q(t)$} & {$[P(t+1)-P(t)] / P(t)$} & {$[Q(t+1)-Q(t)] / Q(t)$} \\
\hline 0 & 4 & $\mathrm{~T}(1)$ & $-1.22 \%$ & $4.28 \%$ & $-0.24 \%$ & $4.28 \%$ & $-2.68 \%$ & $3.41 \%$ \\
\hline 1 & 1 & $\mathrm{~T}(2)$ & $-0.21 \%$ & $-0.56 \%$ & $-1.98 \%$ & $-3.18 \%$ & $0.00 \%$ & $-4.60 \%$ \\
\hline 1 & 2 & $\mathrm{~T}(3)$ & $-3.76 \%$ & $12.73 \%$ & $-1.18 \%$ & $-1.71 \%$ & $-0.74 \%$ & $8.38 \%$ \\
\hline 1 & 3 & $\mathrm{~T}(4)$ & $-1.24 \%$ & $-1.35 \%$ & $-6.88 \%$ & $5.74 \%$ & $-2.00 \%$ & $6.21 \%$ \\
\hline 1 & 4 & $\mathrm{~T}(5)$ & $8.35 \%$ & $1.36 \%$ & $12.83 \%$ & $-12.27 \%$ & $7.25 \%$ & $-4.16 \%$ \\
\hline 2 & 1 & $\mathrm{~T}(6)$ & $-3.85 \%$ & $-23.78 \%$ & $0.00 \%$ & $-33.74 \%$ & $7.90 \%$ & $32.53 \%$ \\
\hline 2 & 2 & $\mathrm{~T}(7)$ & $2.61 \%$ & $28.78 \%$ & $5.97 \%$ & $37.86 \%$ & $0.00 \%$ & $4.11 \%$ \\
\hline 2 & 3 & $\mathrm{~T}(8)$ & $4.49 \%$ & $19.33 \%$ & $0.00 \%$ & $5.89 \%$ & $-0.89 \%$ & $-33.15 \%$ \\
\hline 2 & 4 & $\mathrm{~T}(9)$ & & & & & & \\
\hline \multicolumn{3}{|c|}{ Cumulative } & $5.17 \%$ & $40.79 \%$ & $8.52 \%$ & $2.87 \%$ & $8.83 \%$ & $12.73 \%$ \\
\hline
\end{tabular}

Source: TOPEXEC results of Russian Managers Course Oct 1996

${ }^{20}$ In the table $\mathrm{P}(\mathrm{t})$ denotes price per unit and $\mathrm{Q}(\mathrm{t})$ quantity of stock at the end of period $\mathrm{t}(\mathrm{t}=1, \ldots, 8)$.

The impact of decisions about stocks does not become evident in the game until the end of year 0 . 
Figure :1 Outcomes of the simulation illustrated 


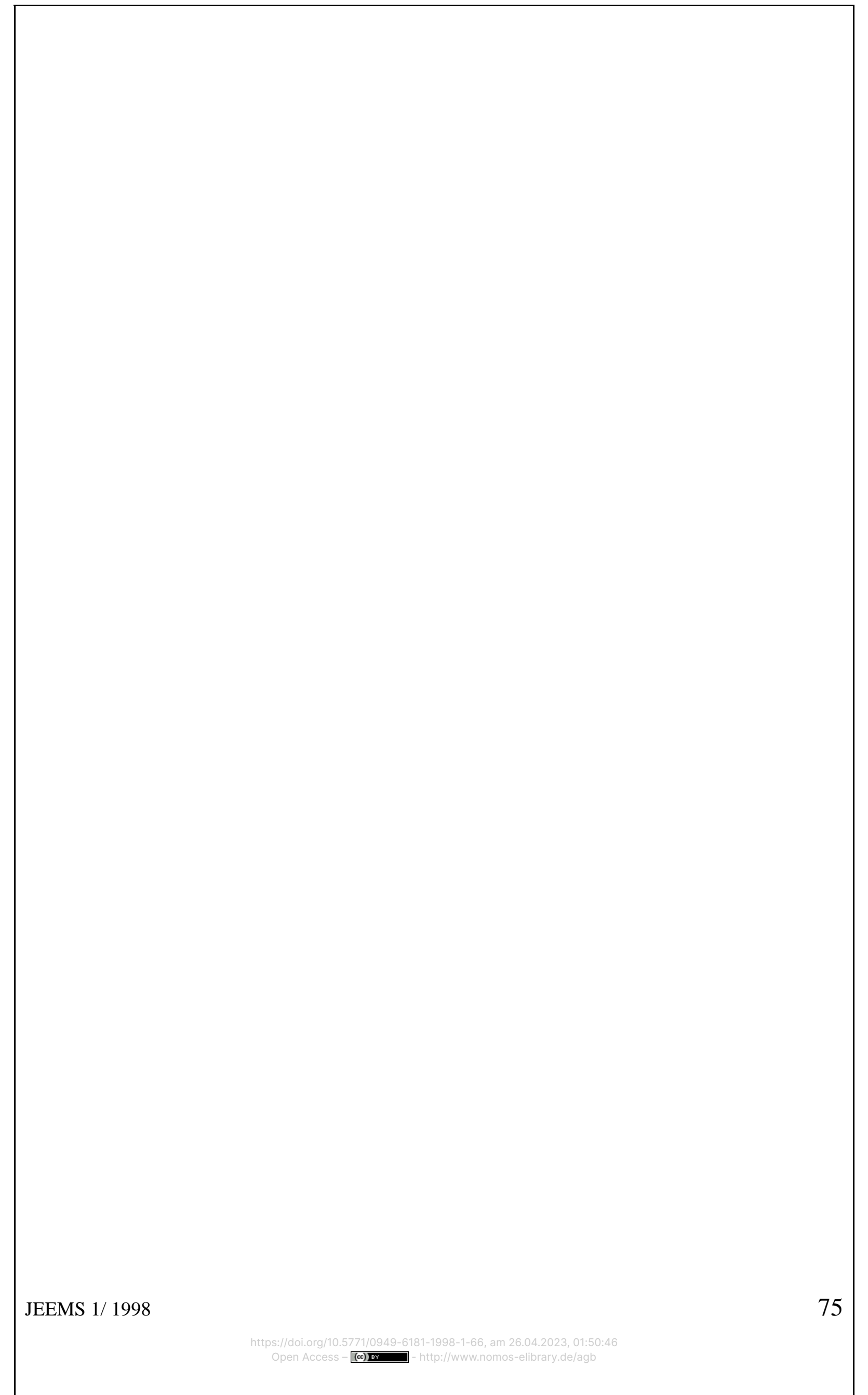


simulation decision making in the Russian teams tends to be hierarchical, with a leader rapidly emerging. The main criteria for leadership seem to rest upon dominant character traits, rather than skills or aptitudes. Once the issue of leadership is decided, decisions are more or less automatically agreed by all members of the team. The leader's decision tends not to be challenged when it is seen to involve contentious issues. Good team players were viewed as those who agreed with their leader rather that those who work well with the leader to reach the right decision.

There are relatively few informal meetings among the Russian teams, and there seems to be little attempt to make use of diverse skills in apportioning work. Although the simulation produces too much data for one person to analyse, and interpret alone, we find a significant reluctance to delegate, or to apportion tasks, and trust subordinates. Instead of developing trust, and a dividing responsibilities, all decisions seem to be discussed collectively, and decided primarily as a result of character dominance.

Whilst all the elements discussed above may exist at the outset in games between Western players, they are gradually eroded: in comparison we find that hierarchical structures tend to be robust in Russian games, even when the team is unsuccessful.

\section{Concluding remarks}

We have sufficient confidence in the existence of a mapping from the focal points we have identified into actual managerial behaviour, to take account of our conclusions and methodology in designing training programmes for Russian managers. We attach most importance to the approach itself. The identification of focal points provides a useful path to the understanding of management culture and its significance for decision making.

The perception of markets as zero sum games suggests that the nature of markets is not understood. Unless the perception is modified, it can become self fulfilling prophesy, with managers refusing to trade, especially in stocks of goods and work in progress, even when such trade is capable of producing mutual benefits. Prices remain rigid in successive games in spite of evidence of substantial excess supply or demand at the firm level.

By control we refer to the process of comparing current and recent performance with plans. The importance given to business environment analysis and accounting, especially management accounting, suggests that although the need for them has been grasped, the significance of controls has not. Although opportunities exist in the game to revise behaviour in response to information about the consequences of past decisions, Russian managers are reluctant to take 
advantage of this by altering prices, engaging in arbitrage over stocks of goods, or revising marketing and research and development expenditures, in the light of evidence of shortfalls between aims and achievements.

The shock therapy model adopted by international institutions and accepted by many Russian reformers involves the following elements (Sachs1995; 1994(a); 1994(b)): liberalising prices, and cutting subsidies; opening the economy to international trade; privatisation and encouraging foreign direct investment; trade led growth and democratic consolidation provided that they do not block the therapy. A problem with such measures is that the drastic redistribution of real income and wealth involved in the process, destabilises the economic reforms that shock therapy is designed to promote, by engendering a feeling of unfairness, and resistance to the market system itself.

The fundamental assumption of shock therapy is that the sudden shift in the business environment that it brings, causes a change in the behaviour of decision makers; it is assumed that the shock is sufficient to shift the focal points of economic behaviour that have adjusted over the years to a command economy, to the kind of (boundedly) rational behaviour that makes a market system work. Focal points, at least in the short and medium term, are more autonomous than the proponents of shock therapy assume. It takes time to adjust, and especially since so much of the change that people experience involves redistribution of income and wealth, it may be legitimate for decision makers to view the market as a zero sum game, in which behaviour inherited from the past is still appropriate.

We are struck by similarity as well as differences in the behaviour of managers across cultures and national boundaries. In the same way as planned and market economies form part of a continuum with market like planning (for example the use of shadow prices within large organisations) and planning like markets (state sponsored regulation, corporatism and industrial policy within market economies), so differences between decision making behaviour by Russian and Western managers are of degree rather than of kind. However the focal points that we have identified, over the period 1993 to 1997 are sufficiently resilient to withstand shocks and determine the nature of the market economy that emerges in Russia.

\section{References}

Dietz, R. (1992): Ten Propositions Towards a Theory of Transformation; From Command to Exchange Communication, in: Sandor Richter (ed): The transition from Command to Market Economies in East-Central Europe, Westview Press, Oxford.

Dyker, D.A. (1992): Restructuring the Soviet Economy, Routledge, London.

Economist (1992): A Survey of Russia, December.

Economist Intelligence Unit, Russia: Country Profile, various issues. 
Hicks, E./ Yeghiazarian, A./ Matthews, R. (1995): Culture And Decision Making Styles Of Russian Managers: A Comparative Analysis, Frontiers in Economic Psycology Proceeding of the 20th IAREP conference, Bergen.

Hayek, F.A. (1949): Individualism and Economic Order, Routledge and Keegan Paul, London.

International Monetary Fund (1992): The Economy of the Former USSR in 1991, Washington, D.C..

International Monetary Fund (1992): Common Issues and Interrepublic Relations in the Former USSR, Washington D.C.

Kreps, D.M., (1987): Nash equilibrium, in: Eatwell, J./ Milgate, M./ Newman, P. (eds): The New Palgrave: A Dictionary of Economics, Macmillan, London.

Kreps, D.M., (1990): Corporate Culture and Economic Theory, in: Alt, J. E./ Shepsle, K.A.: Perspectives on Political Economy, Cambridge University Press.

Liebenstein, H., (1966): Allocative Efficiency vs. X-Efficiency, in: American Economic Review, Vol. LVI.

Matthews, R./ Harry, K., (1993): The Russian Firm: Managing Chaos in Vladivostok, in: European Business and Economic Development, Vol.2, Part 2.

Myerson, R.B. (1991): Game Theory: Analysis of Conflict, Harvard University Press, London.

Nash, J. (1951): Non Cooperative Games, in: Annals of Mathematics, 54.

Porter. M. (1985): Competitive Advantage: Creating and Sustaining Superior Performance, Collier Macmillan, London.

Roth, A.E./ Schoumaker, F. (1983): Expectations And Reputations In Bargaining, in: American Economic Review 73, pp 362-372.

Sachs, J.D. et al (1995): Economic reform and the process of global integration, in: Comments Brookings Papers on Economic Activity, Issue, 1.

Sachs, J.D. (1994a): The prospects for reform in Russia, in: Canadian Business Review, Vol: 21, Issue, 3.

Sachs, J.D./ Wyplosz, C. (1994): Too little, too late?, in: East European Markets, Vol: 14, Issue, 2.

Sachs, J.D. (1994b): Russia's struggle with stabilization: Conceptual issues and evidence, in: World Bank Research Observer, Annual Conference Supplement.

Schumpeter, J.A. (1942): Capitalism, Socialism and Democracy, George Allen and Unwin, London.

Schelling. T. (1960): The strategy of Conflict, Harvard University Press.

Simon, H.A. (1982): Models of Bounded Rationality. 2 Vols, Cambridge Mass., MIT Press.

Varian, H. (1987): Measuring the Deadweight Costs of DVP and Rent Seeking Activities, Mimeo, University of Michigan. 
